\title{
Fraude a la ley y fraude a la ley fiscal: Juegos de estrategias
}

\author{
Legal fraud and tax fraud: Games of strategy
}

\section{Andrés Blanco}

Universidad de la República, Uruguay

\begin{abstract}
RESUMEN Lo que se llama fraude a la ley es una confrontación de estrategias. De un lado, se aprovecha el formalismo de las categorías jurídicas y el modelo argumentativo exegético que impera en la práctica de los juristas para eludir una prohibición legal evitando deliberadamente ingresar en el universo de casos prohibidos. Del otro lado, los que tratan de repeler esa conducta usan una estrategia consistente en la apelación discursiva a fines y principios. Pero las motivaciones de unos y otros están en la prevalencia de sus respectivos intereses, principalmente económicos. El fraude a la ley fiscal de los particulares se produce cuando se usa el formalismo jurídico para defender los intereses de los propietarios de dinero, a la vez que la Administración confronta ese uso con una estrategia que recubre su interés recaudatorio.
\end{abstract}

PALABRAS CLAVE Fraude a la ley, argumentación jurídica, tributos.

ABSTRACT The legal fraud is a confrontation of strategies. On one hand, someone takes advantage of the formalism of legal categories as well as of the exegetic argumentative model that prevail among in the law practice, in order to elude a prohibition by means of avoiding to get into the universe of cases prohibited. On the other hand, those who try to reject that behavior use a strategy consisting in arguing principles or ends of the law. But in material terms, the motives of the involved parties are the opposite interests, mainly economics. The tax legal fraud, or tax avoidance, occurs when the legal formalism is to defend the interests of the money's owners, while the Tax Administration confront such use with a strategy that recovers its collecting interest.

KEYWORDS Legal fraud, legal argumentation, taxes. 


\section{Introducción}

Recientemente se ha discutido públicamente en varios países ${ }^{1}$ la utilización de sociedades, habitualmente constituidas en países de baja tributación, para disminuir los impuestos a pagar en el país de residencia de la persona o de ubicación de un bien. Esto no es novedoso: se trata del fenómeno llamado históricamente fraude a la ley.

El fraude a la ley fue una figura reconocida primero por la dogmática civil, que luego se proyectó hacia otras dogmáticas, como la tributaria y la del derecho internacional privado. A modo de introducción, digamos que en el campo civil el fraude a la ley se suele definir como la colocación artificial de la persona en una posición en la que logra efectos jurídicos más ventajosos que aquellos que tendría si se colocara en su posición que se supone normal de acuerdo al contexto jurídico. ${ }^{2}$ Asimismo, la dogmática suele sostener que el fraude a la ley es diferente del mero engaño o la simulación.

En el campo tributario el panorama es aparentemente más complejo. Si bien muchos juristas hablan del fraude a la ley fiscal, la dogmática tributaria no es homogénea en sus denominaciones y categorías; por ejemplo, aparecen nombres y dicotomías como evasión y elusión, principio de la realidad, ahorro del impuesto y fraude a la ley, etcétera, que por lo demás cada autor delimita a su gusto, con la consiguiente confusión del lector lego (Rosembuj, 1994 69, 85; Kruse, 2002: 592, 603; Brooks, 1997: 96). De todas formas, si se despeja la acumulación de nombres, el problema es el mismo que en materia civil: hay ciertos casos que suponen que una persona se coloca artificiosamente en una posición que le significa disminuir los tributos que debería pagar en caso de tener el tratamiento tributario normal para su situación. La aparente diferencia es que la dogmática tributaria (o una parte importante de ella) parece admitir que existen situaciones en las que también la persona se coloca deliberadamente en una situación que le significa pagar menos tributos, y que sin embargo no debe considerarse fraudulenta, ilícita, etcétera. Esto último es lo que se denomina ahorro lícito de impuestos o elusión legítima.

En este trabajo no me interesa abordar el fraude a la ley desde un punto de vista interno o dogmático, es decir proponiendo respuestas jurídicas al problema de cuándo debe entenderse que hay fraude a la ley, y cuándo no lo hay, ni cuáles son los efectos jurídicos de su consumación. Aunque no es del caso analizar las limitaciones del abordaje dogmático, la propuesta de analizar el fraude a la ley fiscal desde una perspectiva no dogmática se basa en el supuesto de que sólo desde fuera de la dogmática podremos saber qué fenómeno social se manifiesta como una cuestión jurídica. Desde luego, esta postura implica una opción epistemológica por una teoría del derecho centrada en los aspectos puramente materiales del fenómeno jurídico. Por lo tanto, la dogmática jurí-

1. El caso denominado Panamá Papers, que involucra el uso de sociedades constituidas en ese país, puede repasarse en el sitio web especial de The International Consortium of Investigative Journalists: https:// panamapapers.icij.org/.

2. Más adelante se señalarán referencias dogmáticas sobre la definición del fraude a la ley; vayan estas reflexiones a modo introductorio. 
dica (y otros discursos jurídicos) no será el marco teórico de la reflexión, sino objeto de ésta. No obstante, en el trabajo se tomará como punto de partida una definición dogmática del fraude a la ley, analizando críticamente sus componentes para luego reformular la figura en perspectiva teórica.

Mi tesis es que el fraude a la ley es un juego de estrategias argumentativas, esto es, un modo peculiar de justificar, mediante argumentos reconocibles como jurídicos, conductas de los particulares, decisiones de autoridades o propuestas de decisión de juristas prácticos y dogmáticos. Por un lado, las conductas que se califican como fraude a la ley se basan en una estrategia que aprovecha el carácter formal de las categorías jurídicas y el modelo argumentativo exegético, mientras que el combate a esas conductas calificándolas como un ilícito específico (precisamente, el fraude a la ley) es una estrategia que busca escapar a los modelos argumentativos habituales. El fraude a la ley fiscal es un caso especial de enfrentamiento de estrategias de estos tipos. A su turno, cada estrategia está determinada por intereses económicos: en el caso de tributo, la defensa de la función recaudadora del Estado, y desde el punto de vista de los particulares, la defensa de la propiedad privada, funciones ambas que son esenciales en la economía capitalista.

\section{El fraude a la ley en general}

\subsection{Descripción de las conductas llamadas fraude a la ley}

Como primer paso para dilucidar el fenómeno social subyacente al fraude a la ley, analicemos el discurso dogmático sobre dicha figura.

La dogmática clásica dice que el fraude a la ley es, aproximadamente, "colocarse en una situación conforme al texto de la ley, pero contraria a su espíritu» o a sus fines (Alfonsín, 1953: 584 y ss.; Messineo, 1979: 479-48o). De similar manera, Atienza y Ruiz Manero (2000: 74) sostienen que el fraude a la ley es una violación de los principios o las reglas morales que subyacen a la ley. Esto es confuso para quien no está familiarizado con las prácticas lingüísticas de los juristas; ¿qué cosa es el espíritu de la ley?; o ¿cómo se hace para saber cuáles son los fines o principios ocultos de un texto? Como habitualmente sucede, la dogmática se parapeta en un lenguaje poco entendible para el lego, que no alude a propiedades reconocibles fácilmente, ni formula enunciados verificables. Salgamos pues de ese mundo y describamos simplemente la conducta de los juristas cuando dicen que hay un fraude a la ley, para proponer un concepto también descriptivo de este fenómeno.

Tomemos un texto positivo cualquiera, que pretenda abarcar un universo de casos definido por una o más propiedades. ${ }^{3}$ Seguramente, dicho texto establecerá que, cuando se reúnan todas las propiedades mencionadas en él, para un grupo de sujetos, una cierta conducta será obligatoria, prohibida o permitida. Por ejemplo: cuando una

3. Empleo aquí un análisis normativo del tipo sugerido en Alchourrón y Bulygin (1998: 52 y ss.). 
persona física (propiedad A), residente (propiedad B), obtenga una renta (propiedad C), por depósitos de dinero, préstamos, créditos y similares (propiedad D), en el país de residencia de la persona (propiedad E) o proveniente de entidades en el exterior (propiedad F), etcétera, para A será obligatorio (O) pagar el Impuesto a las Rentas de las Personas Físicas (IRPF) a tal tasa, sobre tal base de cálculo, etcétera (I). Es decir: Si A, B, C, D, (EvF),...n $\rightarrow \mathrm{OI}(\mathrm{A})$, es decir, «si se dan todas las propiedades, para A es obligatorio I». ${ }^{4}$

Suponiendo un jurista medio, podemos pensar que su primer abordaje de un caso será bastante paralelo al texto positivo: intuyendo, por un contexto de conocimientos previos, que una cierta situación puede estar comprendida en un universo de casos (por ejemplo, que un depósito en el exterior puede generar intereses gravados por un impuesto a la renta), comparará las propiedades del caso con las que surgen de una lectura normal del texto y llegará a una cierta conclusión normativa.

Cuando decimos que hay un fraude a la ley, en cambio, las prácticas son un tanto diferentes. En primer lugar, hay: a) un sujeto que cumple la mayoría de las propiedades de un universo de casos, pero ha evitado deliberadamente configurar una (o unas pocas) de ellas, quedando fuera de dicho universo; o b) un sujeto que ha configurado deliberadamente las propiedades que le permiten estar dentro de un universo de casos. A cuenta de lo que se comentará más adelante, observemos desde ya que estas conductas suponen normalmente un manejo experto de los textos, pues de otra forma es difícil configurar o evitar deliberadamente las propiedades que el mismo indica. $\mathrm{Y}$, como consecuencia de lo anterior, también es una señal de que detrás de esa conducta está la mano de un jurista profesional (o al menos de alguien versado en derecho) que hizo un diseño estratégico de la conducta de ese sujeto.

Ante esa colocación más que intencional en un universo de casos, o fuera de él, el sujeto involucrado puede toparse con otro u otros sujetos que deseen lo contrario: incluirlo en el universo de casos, si lo evitó, o excluirlo, si se incluyó en el mismo. Para ello, ese o esos contrincantes deben agregar o quitar propiedades diferentes de las mencionadas de manera más o menos explícita en un texto, para ampliar o reducir el universo de casos hasta un punto que les permita decir que el sujeto que deliberadamente quedó dentro o fuera del universo de casos está en realidad en el lugar opuesto al que pretende. Esas propiedades que se excluyen o se agregan se encubren con los nombres fines de la ley, principios, etcétera.

Supongamos, en el ejemplo impositivo que utilicé, que una persona física residente en el país obtiene un interés por un préstamo otorgado a una persona física del exterior, y esa persona física del exterior luego ingresa el dinero en una sociedad (digamos, dándole a su vez otro préstamo), que es la que realmente requiere esos fondos para sus actividades. El prestamista evitó deliberadamente, configurar la propiedad $\mathrm{F}$ de mi ejemplo: que la renta se obtenga de una entidad del exterior, porque esa persona física

4. Como es habitual en las notaciones lógicas, el símbolo «V» denota la disyunción incluyente, esto es, la posibilidad de integrar el universo de casos por cumplir alternativamente una u otra propiedad. 
que toma el préstamo no lo es. Advertido de esa estrategia, es posible que otro sujeto (por ejemplo, la Administración tributaria o un juez) sostenga que el impuesto se aplica no sólo cuando la renta de fuente extranjera se obtiene de una entidad entendida como persona jurídica, sino también de una persona física actuando por cuenta de una entidad $u$ otro sujeto que desarrolla una actividad empresarial. En tal caso se está agregando una tercera propiedad alternativa (no acumulativa) para definir el universo de casos. La lectura primaria de la ley que propuse antes nos había definido el universo de casos del siguiente modo: $\mathrm{Si} A, \mathrm{~B}, \mathrm{C}, \mathrm{D},(\mathrm{E} v \mathrm{~F}), \ldots . n \rightarrow \mathrm{OI}(\mathrm{A})$.Pero la propuesta antifraude nos propone esta definición del universo de casos: $\mathrm{Si} A, \mathrm{~B}, \mathrm{C}, \mathrm{D},(\mathrm{E} \vee \mathrm{F} \vee \mathrm{G}), \ldots n \rightarrow \mathrm{OI}(\mathrm{A})$. Es decir, se agrega a $\mathrm{G}$ a la definición del universo de casos, que es la propiedad obtener la renta de una persona física que actúa a nombre propio, pero por cuenta de una entidad u otro sujeto que desarrolle una actividad empresarial, del exterior.

Hasta aquí una descripción lingüística de cómo se construye un caso de fraude a la ley. Veamos ahora cómo se inserta esta figura en el contexto de la praxis jurídica.

\subsection{El fraude a la ley como ilícito}

Los autores dogmáticos suelen decir que el fraude a la ley es una modalidad especial de acto ilícito. El concepto de ilícito puede ser un buen inicio del análisis, pero partiendo de una definición de ilicitud descriptiva, que es la única que cumple con el propósito de un enfoque teórico en sentido estricto.

Con algunas variaciones, utilizaré la concepción de ilícito de Kelsen (1997: 125-129). Según este autor, el ilícito se define por la aplicación de una sanción: no es que existan actos que de antemano son ilícitos y por ese motivo se les asocia una sanción, sino que el acto es ilícito porque se le asocia una sanción. Esto significa literalmente que los ilícitos son creados por las autoridades en el momento en que aplican una sanción, no antes. Como en toda praxis, los actos (en este caso, los actos de la autoridad) son guiados o justificados por un discurso, pero - valga la redundancia- esos discursos son guías o justificaciones que se añaden al acto de autoridad; éste vale por el hecho social de que se acepte el poder de quien lo dicta y especialmente que se acepte que ese poder se traduzca en el ejercicio de la violencia. La aplicación de una sanción por esa autoridad es lo que convierte al acto en prohibido.

Con esta concepción de ilícito, el fraude a la ley será un ilícito sólo cuando sea atacado por un tercero, y una autoridad (juez o administración) impulse una sanción para el que realizó el acto. Pero eso no significa ninguna diferencia con un ilícito típico, esto es, con un acto que es asociado con una sanción en un texto autorizado leído en forma estándar.

Podemos ir más allá, y observar si hay alguna diferencia a partir del conocimiento general de la ilicitud del acto. En efecto, la ilicitud tiene un efecto directo respecto del acto concreto que es sancionado, pero también reprime las conductas prohibidas en la medida en que las personas sepan que tal o cual conducta no puede hacerse, lo cual deriva del conocimiento de un texto (para un jurista o una persona versada en derecho), 
o simplemente de una creencia divulgada informalmente en la sociedad. Si alguien se decide a hacer lo que no puede hacerse no verá ningún efecto material que sea una consecuencia normativa del acto a la sola luz de la ley, aunque su comportamiento encuadre perfectamente en el conjunto de conductas que la ley prohíbe. El sujeto empezará a observar algún efecto cuando se despliegue a su respecto la acción de la autoridad, y más todavía cuando se haga efectiva la sanción. Por ejemplo: si una persona mata a otra, empezará a sentir los efectos de la prohibición de matar no como un efecto del Código Penal en tanto texto, sino bajo la forma de una persecución policial, una indagatoria judicial y, quizás y al final, como una reclusión en una cárcel.

Ese efecto difuso es sustancialmente igual en el ilícito típico que en el ilícito atípico. Por ejemplo, partiendo del conocimiento de que la ley de su país establece que el régimen patrimonial de una unión se rige por la ley del primer domicilio de la pareja, una cierta pareja fija su primer domicilio en el extranjero, siquiera por un par de meses, para evitar el régimen patrimonial de su país de residencia real y acogerse a su similar de ese Estado extranjero. Los miembros de esa pareja sentirán un efecto directo de la ilicitud de esa conducta, por ejemplo, un tercero promueva una acción contra ellos, o todavía más, cuando un juez desconozca un negocio, argumentando que han manejado fraudulentamente el punto de conexión, o abusado de su derecho de fijar un domicilio común. Antes de ponerse en marcha el aparato judicial para reprimir su conducta, existe también un efecto difuso de entrever que esa conducta está prohibida. La diferencia está en que las prohibiciones eludidas mediante el fraude son más sutiles, por lo que conocer que eso es un posible ilícito requiere un conocimiento más refinado, o más dinero para pagar honorarios de juristas asesores, para generar la creencia en la prohibición.

De todas formas, este ejemplo nos aporta un dato importante acerca de quiénes suelen ser protagonistas del fraude a la ley. Dado que esta figura supone la evitación o configuración deliberada o forzada de una (o unas pocas) propiedad definitoria de un universo de casos jurídicamente relevantes, ella no es posible sin una lectura experta de los textos jurídicos, que sólo puede hacerse por juristas profesionales. Además, como el fraude a la ley tiene un contenido de protección del patrimonio, en principio sólo tendría sentido para personas que tienen bienes en cantidad suficiente como para plantearse estrategias especiales para su defensa de posibles ataques de terceros. Es decir, el fraude a la ley es, en principio, relevante para grupos reducidos de personas, y es irrelevante para la mayoría.

En resumen: una diferencia entre los ilícitos comunes y el fraude a la ley y otros ilícitos atípicos es que aquellos normalmente consisten en sanciones por conductas en las que no se calcula ni se medita la posible sanción por parte de la autoridad, mientras que en el fraude a la ley y otras conductas similares se monta una estrategia para combatir una pretensión de aplicar una sanción, que de antemano se ve como probable. 


\subsection{El fraude a la ley como juego de estrategias argumentativas}

Al final del apartado anterior quedó planteada la particularidad del fraude a la ley y otras figuras semejantes: tanto la conducta presuntamente fraudulenta (o abusiva) como la oposición a la misma se fundamentan en estrategias de acción que, a la postre, derivan en estrategias argumentativas. Pero esa diferencia es incomprensible sin algunas consideraciones generales acerca del discurso de los juristas en general.

\subsubsection{Argumentación jurídica y categorías jurídicas}

El derecho es una praxis social que organiza el ejercicio del poder y la violencia sociales, pero no al azar sino con una función: dirigir la vida social de un modo que permita que la estructura económica vigente se mantenga y se reproduzca (Blanco, 2015: 56-62). Esta característica supone varias cosas, de las cuales quiero detenerme en dos. Primero, como el sistema económico vigente requiere reconocer la autonomía de los individuos, pues de otra forma no se puede generalizar totalmente el intercambio de mercancías, y ello es un rasgo definitorio del capitalismo (Pašukanis, 1976: 93 y ss.), el ejercicio del poder tiene que revestirse de argumentos, porque un sujeto autónomo (siquiera nominalmente) no acepta indefinidamente la autoridad ejercida como pura violencia bruta. Además, el sistema económico también requiere que el ejercicio del poder tenga cierta previsibilidad, para contrapesar la tendencia económica natural del capitalismo a la inestabilidad (Weber, 1998: 512 y ss.).

Cuando ambas necesidades de la economía confluyen en el derecho, nace el positivismo ideológico o exegético: las decisiones se justifican mediante argumentos que se enlazan con cierta facilidad con textos normativos generales, como constituciones, leyes, reglamentos, etcétera. Obsérvese la descripción general y el ejemplo de fraude a la ley que propuse en 2.1: el abordaje jurídico de una situación siempre se piensa (inclusive yo mismo lo pienso) como una subsunción en un texto, y los problemas surgen - aparentemente- a partir de discrepancias acerca de cómo ese texto define el conjunto de casos que abarca. Ésta es una forma de razonar jurídicamente que predomina casi excluyentemente hasta hoy mismo como autocomprensión de sus prácticas por los juristas (Guastini, 2014: 41, 55 y ss.).

De esas necesidades de la estructura económica, y estrechamente ligadas con el modelo argumentativo exegético, nacen las categorías jurídicas, que coinciden aproximadamente con lo que Kelsen llamó estática jurídica (Kelsen, 1997: 123 y ss.).

Hay categorías muy genéricas como norma, obligación, etcétera; y otras más específicas: contrato, y dentro de éste compraventa, préstamo, etcétera; persona jurídica, y dentro de éstas sociedad, asociación, etcétera; impuesto, y dentro de éste impuesto a los bienes inmuebles, impuesto al valor agregado, etcétera; y así sucesivamente. Cada categoría jurídica se define mediante una técnica consistente en expresar ciertas propiedades, cuya conjunción define universos de casos (en eso consiste el método de trabajo 
de Alchourrón y Bulygin al que aludí en el punto 2.1), a los que se asocian cualidades normativas (por ejemplo, el vendedor está obligado a saneamiento en la compraventa).

Lo interesante es ver cómo se delimitan las propiedades relevantes para definir un universo de casos jurídico. Lo primero es que no todas las propiedades posibles, especialmente las fácticas, están presentes entre las propiedades jurídicamente relevantes; por ejemplo, en una compraventa no es relevante si el sujeto que compra obtuvo el dinero por endeudamiento o mediante ingresos propios, si el objeto comprado es de uso vital o un despilfarro, si el comprador o el vendedor son buenas personas, etcétera. Por otro lado, las propiedades normativas frecuentemente están oscurecidas, aparentando ser propiedades fácticas; por ejemplo, se dice en el préstamo de cosa fungible el prestatario se hace propietario de la cosa prestada, como si ser propietario fuera un hecho natural. El derecho, cuando delimita una categoría jurídica, construye lo que Frege llama sentido para hablar de un objeto: de todo el elenco posible de propiedades de un referente (esto es, un hecho externo a la experiencia subjetiva del sujeto), algunas propiedades se toman en cuenta mientras que otras propiedades son descartadas. Por eso se puede hablar de un mismo referente en muchos sentidos, dependiendo de las propiedades que se elijan en cada caso (Frege, 1998: 84-139). Así, y aunque las categorías jurídicas engloban relaciones sociales, éstas son definidas en el discurso jurídico de un modo distinto del que lo hacen un teórico social o una persona común; en particular, el derecho omite gran parte de las propiedades de una relación económica derivadas de su contexto social más amplio. Es por esto que puede decirse que el derecho mistifica (es decir, presenta en forma alterada) las relaciones sociales (Pašukanis, 1976: 67).

Respecto de las categorías jurídicas hay, para los juristas, un compromiso ontológico, utilizando palabras de Quine (Quine, 2002: 13 y ss.). Los discursos generan, por diversos motivos, diferentes formas de agrupar propiedades y dar, a los conjuntos que resultan de ese agrupamiento, nombres. Quien es partícipe de un discurso debe asumir esas categorías y nombres (esos sentidos de los objetos, diría Frege) para desenvolverse dentro del mismo, y también debe, como regla, despreciar las propiedades materiales que en ese discurso se han descartado, pues de lo contrario se arriesga a quedar fuera del diálogo con los otros partícipes. En el discurso jurídico, como consecuencia del modelo argumentativo exegético, las propiedades que delimitan una categoría, como regla, deben buscarse sólo en los textos autorizados de la ley, en lecturas normales de los mismos. Eso es lo que Weber llamaba cualidad formal del derecho (Weber, 1998: 606-607; Luhmann, 1983: 130-135).

Por ejemplo, la función económica que cumplen las sociedades, o más genéricamente las personas jurídicas (protagonistas frecuentes de fraudes a la ley), no es tanto la confluencia de varias personas para compartir suertes (affectio societatis), sino la atribución a esa entidad de un patrimonio diferente del patrimonio personal de su o sus integrantes. Retomando la referencia de Weber acerca de la predictibilidad de las decisiones como condición necesaria del capitalismo, tiene que ser predecible el volumen total de capital arriesgado: siquiera en forma aproximada, tiene que existir una cota 
para las pérdidas, pues de lo contrario se destruiría capital en cantidades que obstarían a su propia reproducción.

Las personas jurídicas sirven pues para preservar el capital, lo cual nada tiene que ver con el reconocimiento de una subjetividad, y también es en buena medida independiente de la intención de compartir beneficios y pérdidas de varias personas. En una economía no mercantil, en la cual no hay ninguna forma de capital, una persona jurídica como unidad patrimonial independiente es inconcebible. Sin embargo, en el discurso jurídico la función de preservar el capital de su destrucción está soslayada o mencionada oblicuamente como limitación de responsabilidad, o separación patrimonial, y en su lugar se enfatizan otras propiedades contingentes, como el deseo de unir suertes, ${ }^{5}$ o propiedades directamente contrafácticas, como la subjetividad, que asimila a un ser humano lo que es simplemente un conjunto diferenciado de bienes.

\subsubsection{Estrategias de uso y de negación del uso de las categorías jurídicas}

Veamos ahora cómo se inserta en ese contexto de argumentos y categorías el fraude a la ley. En su faz propiamente normativa, el discurso jurídico prohíbe las conductas disfuncionales, en principio mediante una técnica que ya se comentó: se describe en forma abstracta, por un texto autorizado (por ejemplo, una ley), un universo de casos, y se ordena que cuando alguien se encuentre con un miembro de ese universo, se aplique una sanción. Si las cosas ocurren de acuerdo a lo previsto por quienes dictaron el texto y por el modelo argumentativo exegético-positivista, dado un miembro del universo de casos prohibidos, tendremos un ilícito (típico).

Ahora bien, es habitual que ciertos intereses y pretensiones, generalmente económicos, pujen por evadir una prohibición prevista por los textos positivos. El compromiso formalista con el alcance de las categorías jurídicas es una invitación para utilizarlas estratégicamente para esos escapes. En efecto, como los juristas y los no juristas educados conocen de antemano el compromiso ontológico con las categorías, y además la predominancia del modelo argumentativo exegético, se evita cuidadosamente una sola o unas pocas de las propiedades que definen el universo de casos prohibidos, o se configuran deliberadamente propiedades que conforman un antagónico universo de casos permitidos.

Por ejemplo, si una persona que quiere evitar la prohibición de sociedades de un solo socio, invitando a otra persona a ser socio, con una participación ridículamente exigua, que no le permite tener ninguna parte significativa de las ganancias, pero que tampoco le implica ningún riesgo de pérdida. Esa conducta es estratégica porque quienes obran de esa forma conocen, siquiera someramente, la práctica argumentativa estándar de los juristas, en la cual prima el texto de la ley y la calificación de una conducta es su

5. La unión de suertes o el deseo de compartir pérdidas son contingentes puesto que muchas legislaciones admiten personas jurídicas en las que no exista pluralidad de socios, o una pluralidad simplemente simbólica. 
subsunción en un conjunto definido formalmente; por ejemplo, sociedad. Por lo tanto, apuestan a que se mantenga esta estrategia argumentativa y se considere que están fuera del universo de casos prohibidos.

Los intereses y pretensiones que apuntan a quebrar estratégicamente una prohibición no sólo pueden manifestarse en los particulares, sino que incluso una autoridad puede actuar de esa forma. Por ejemplo, pongamos el caso de una Constitución que prohibiera establecer impuestos sobre dividendos no distribuidos, y supongamos que en ese país una ley establece un impuesto sobre los resultados acumulados no distribuidos pero calificados como activos, y teniendo como contribuyente a las sociedades que generan esas utilidades. Esa ley estará eludiendo estratégicamente la prohibición por la vía oblicua de considerar esas utilidades como activos de la sociedad, calificación que evita deliberadamente mencionar que, desde el punto de vista del socio, son utilidades no distribuidas.

Ahora bien, a esas estrategias se responde con otras. Los intereses y pretensiones favorables a una prohibición, ante una estrategia de evasión de la prohibición que aproveche el carácter formal de las categorías jurídicas, no pueden seguir recurriendo a los argumentos exegéticos tradicionales fundados en lecturas normales o estándares de la ley, la Constitución o el reglamento, porque en ese terreno tienen la batalla perdida. La estrategia de argumentación tiene que cambiar, y tiene que echar mano de ciertas «reservas argumentativas»: las denominaciones tradicionales de estas reservas argumentativas eran "espíritu de la ley», "fines de la ley», y cosas semejantes, mientras que sus nombres a la moda de hoy son «principios», «derechos» $\mathrm{y}$ «directrices». El patrón, sin embargo, es el mismo: son fórmulas lingüísticamente vagas que se remodelan a gusto por el dogmático, juez, autoridad administrativa, abogado, etcétera. Por lo tanto, los «fines de la ley», los "principios», etcétera, tienden, por su laxitud lingüística (la cual es deliberada), a sostener prácticamente cualquier tipo de argumentos, con lo cual se vuelven recursos argumentativos centrales cuando se está fuera del esquema argumentativo exegético. No es, entonces, que el fraude a la ley se sancione en base a "principios» $\mathrm{o}$ «fines», antes que atendiendo a «reglas» o la «letra de la ley»: siempre se resuelve en función de los intereses sociales, y cuando éstos no pueden justificarse fácilmente mediante textos positivos, se inserta en el discurso de justificación un principio o un fin que haga lo propio.

Por eso es que el fraude a la ley es un juego de estrategias argumentativas: una que echa mano del modelo argumentativo estándar, y otra que le sale al cruce con argumentos de construcción no estándar. Algunos rasgos importantes de este juego estratégico, que luego desarrollaré con mayor extensión en la materia fiscal, son: a) el fraude a la ley es un juego estratégico semejante a otros que tienen igual propósito («interpretación extensiva», «integración», etcétera); b) sin embargo, históricamente el recurso al «fraude a la ley» para combatir el uso de categorías y argumentos estándar, ha sido una estrategia (o mejor dicho, una «contraestrategia») secundaria o subsidiaria, en razón del arraigo que tiene la creencia ideológica en los «significados únicos» de los textos los juristas, la que hace preferibles otros recursos argumentativos en vez del fraude a la ley. 


\subsubsection{Otros rasgos del fraude a la ley y otras figuras semejantes}

Si deseamos llegar al fondo del problema e identificar los intereses en pugna, nos toparemos con un problema teórico que desborda la teoría del derecho en sentido estricto, ya que atañe a la estructura social y económica profunda y, epistemológicamente, es un problema cuya solución depende del paradigma que se adopte para explicar la economía y la sociedad. En el paradigma económico neoclásico, las estrategias argumentativas son la expresión de una motivación general a maximizar la utilidad individual, entendida como patrón universal de la conducta (Carrasco Perera, 2016: 39 y ss.). Mi punto de vista, en cambio, es que los intereses en pugna se segmentan y orientan en función de grupos, que a su vez se conforman de acuerdo a las diferentes relaciones sociales a través de las cuales las personas se apropian del ingreso. No hay pues intereses ni motivaciones económicas universales: cada grupo social tiene, en función de su propia posición en la estructura económica, intereses y motivaciones divergentes. De esta forma se explica que existan, dentro de la gran familia del abuso, el fraude a la ley y figuras semejantes, subconjuntos identificables: por ejemplo, los abusos o fraudes a la ley que encubren relaciones de trabajo subordinado sólo se producen como producto de los intereses de los empresarios que emplean trabajadores, y no entre los pequeños productores que no emplean trabajadores. Ésta es una concepción que, en forma flexible, recoge los supuestos de Marx en cuanto a la definición de las «clases sociales», y la proyección de sus intereses a diferentes discursos (Marx, 2000: 817-818).

Otro rasgo importante de las estrategias argumentativas, tanto favorables como adversas a esta utilización estratégica de las «categorías jurídicas», es su parentesco con los programas político-jurídicos, que Kennedy (1997: 287 y ss.). ha llamado ideologías jurídicas. Estos programas o ideologías son grandes visiones del fenómeno jurídico enlazadas con grandes visiones de la estructura social y la economía, que operan como sustratos explícitos o subyacentes de la producción del discurso jurídico, influyendo en la delineación de argumentos, en las «interpretaciones» de los textos, en la forma de decidir casos difíciles, etcétera. Kennedy sostiene (y creo que es acertado) que en la cultura jurídica occidental existen dos grandes programas político-jurídicos: uno que podríamos llamar «social intervencionista», proclive - entre otras cosas- a restringir la libertad total de las empresas, a favorecer la intervención estatal en las relaciones económicas privadas, a favorecer sectores sociales que se entienden desfavorecidos (trabajadores, minorías étnicas, minorías sexuales, etcétera); y otro programa que podríamos llamar «liberalconservador», proclive - entre otras cosas- a la libertad de acción de las empresas, la no intervención del Estado en las relaciones económicas privadas, etcétera.

Estos programas o ideologías jurídicas son muy útiles en discusiones como las del «fraude a la ley», ya que son una fuente de «argumentos ad hoc» o abiertamente políticos, especialmente relevantes cuando falla la argumentación jurídica estándar. Por ejemplo, cuando se utiliza estratégicamente una «sociedad» para evitar a los acreedores, el programa liberal-conservador proporciona un argumento relevante: la defensa de la «autonomía de la voluntad». 


\subsection{Crítica del «fraude a la ley» como «violación de fines» y como «violación de principios»}

Podemos ahora someter a crítica a la dogmática tradicional, que define al fraude a la ley como una «violación del espíritu de la ley», o la persecución de «fines contrarios a los de la ley», aunque nominalmente se respete el «texto» (Alfonsín, 1953: 588 y ss.; Messineo, 1979: 480), así como a Atienza y Ruiz Manero, que lo definen, junto con otros «ilícitos atípicos», como «violaciones a los principios» (2000: 74-79).

La descripción hecha en 2.1 es en sí misma una crítica a las definiciones dogmáticas de "fraude a la ley»: en términos lingüísticos, atacar una conducta llamándola «fraude a la ley» es agregar propiedades a las que surgen de una lectura estándar de un texto, con lo cual se agranda el universo de casos abstractamente considerados. No es necesario, pues, acudir a ningún «fin» ni «principio» para describirlo; los «fines» $\mathrm{y}$ «principios» tienen sólo el fin retórico de justificar la agregación de propiedades no previstas en el texto legal, constitucional o reglamentario.

Las tesis que apelan al «espíritu», los «fines» o los «principios» deben descartarse si se pretende hacer un análisis del «fraude a la ley» ajeno a la metafísica. Siguiendo a Carnap (1993), entendamos por «metafísica» la proposición de entidades totalmente ajenas a la experiencia empírica. Si aceptamos además que la metafísica, así entendida, debe separarse de la teoría entendida como «ciencia», proponer "principios» $\mathrm{O}$ «fines» es, efectivamente, una propuesta metafísica. Y no sólo son metafísicos los «principios» $\mathrm{y}$ «fines»: una noción tan cara a la dogmática jurídica occidental como la «norma jurídica», como ente que rebasa los simples textos físicos, también es metafísica, y no puede ser tomada como objeto real de estudio teórico. Examinemos en detalle estas afirmaciones.

Los nombres, y una de sus versiones como las "normas», son simples generalizaciones del lenguaje y quizás - a lo sumo- representaciones psíquicas, pero no necesariamente objetos reales. La definición de un «objeto real» es por cierto problemática; en definitiva, todo se resume en agrupar ciertas propiedades, seccionándolas de otras propiedades, y llamar a ese conjunto de propiedades - por ejemplo- humanidad, árbol, etcétera. Pero, y he aquí lo importante, siempre se trata de propiedades con asiento empírico. Volviendo a los compromisos ontológicos que mencioné en 2.1, tomándolos de Quine, la crítica de Carnap a la metafísica, que yo utilizo para objetar las nociones dogmáticas de norma, principio, fin, etcétera, asume un compromiso ontológico: el de la concepción occidental clásica de ciencia, que delimita objetos sólo a partir de propiedades observables. En mi opinión, en un ámbito teórico es preferible el compromiso ontológico de la ciencia antes que el compromiso ontológico de los juristas. El motivo es que el discurso de la ciencia tradicional ha aceptado su sujeción a la crítica más amplia y una mayor disposición a abandonar sus enunciados y sus propias categorías de objetos, bajo el supuesto de que de algún modo la realidad de desenvuelve con cierto grado de independencia del propio lenguaje.

Por ese motivo, no tiene sentido postular ni el conjunto mayor norma jurídica, ni 
sus subconjuntos principios y reglas (Dworkin, 1993: 72 y ss.; Atienza y Ruiz Manero, 1996: 6 y ss.), ${ }^{6}$ ya que estas tesis suponen entes ajenos a toda experiencia empírica. Como mucho, lo que se llama norma, sea regla o principio, no pasa de ser una creencia más o menos generalizada acerca de una prohibición o permiso.

Adicionalmente, la creencia en la norma jurídica como ente real, y con mucha más razón la creencia de que es posible conocer objetivamente principios o fines normativos, es ideológica, entendiendo por ideología a los discursos que presentan visiones del mundo sustraídas a la crítica y que tienen origen en intereses (Correas, 2003: 77-83; Courtis, 2006). ${ }^{7} \mathrm{Al}$ sostenerse que un enunciado normativo está designando una entidad real, en vez de simplemente dirigir la conducta, se induce a pensar que las normas están fuera del alcance de los hablantes. Cuestionar una norma es cuestionar el hecho social del poder; pero se lo presenta ante la gente como un cuestionamiento de un hecho objetivo (justamente, la norma) para defender el mantenimiento de ese poder.

\section{El fraude a la ley fiscal}

\subsection{La base económica del fraude a la ley fiscal}

Llegamos entonces al fraude a la ley fiscal, que es la versión tributaria del fraude a la ley en general. La dogmática jurídica tributaria suele definirlo extrapolando la definición general del fraude a la ley: para esta postura el fraude a la ley fiscal es la realización de un negocio que evita o disminuye una deuda tributaria de un modo que no se aparta del texto de la ley, pero que vulnera sus fines o propósitos (Faget, 1981: 197-202; Rosembuj, 1994: 125 y ss.; Tarsitano, 2001: 92 y ss.; Ferreiro Lapatza, 2003: 519).

Sin embargo, en la perspectiva que he adoptado, el fraude a la ley fiscal es un choque de estrategias argumentativas para justificar ciertas decisiones en materia tributaria. Como la elección de una estrategia argumentativa deriva de la necesidad de hacer prevalecer un interés, lo primero es definir los intereses en pugna en la tributación. Para eso es necesario describir las funciones (y contrafunciones) del tributo en la economía y la sociedad.

En ese sentido asumo la concepción del tributo de la teoría poskeynesiana del circuito monetario: dado que el Estado y el sector financiero crean constantemente dinero para poder realizar el intercambio de mercancías en el que desemboca la producción capitalista, el tributo es una de las formas (la forma por excelencia) de destrucción sistemática de dinero. Si la masa monetaria creciera constantemente, los precios se elevarían también en forma constante una vez que se llega al límite de lo que las empresas quieren producir y vender. Como esa elevación permanente de precios es sentida como una anomalía por los empresarios, ya que disminuye sus posibilidades de hacer previsiones, tiene que existir un mecanismo permanente de eliminación de dinero cir-

6. Limito las referencias porque un repaso no ya exhaustivo, sino somero, de la literatura sobre principios y derechos insumiría por sí solo un artículo completo.

7. Vale también respecto de la ideología la misma restricción de las citas por motivos de brevedad. 
culante: ese mecanismo es el tributo, que a través de la recaudación quita dinero de las manos de los particulares. El tributo es, por lo tanto, una pieza totalmente funcional a la economía capitalista (Bougrine y Seccareccia, 2006).

Ahora bien, esta funcionalidad de los tributos choca con una relación social central y definitoria en la economía capitalista, y en todas las economías mercantiles: la propiedad privada. Digo que la propiedad privada es una relación social, porque materialmente encaja en la descripción de relación social de Weber (Weber, 1998: 17-18): es un conjunto de acciones sociales orientadas hacia otros, consistentes en una serie de actos de personas sobre cosas (usar un objeto, trasladarlo, etcétera), y otra serie de actos de otras personas consistentes, mayormente, en abstenciones (de usar ese mismo objeto, trasladarlo, etcétera).

Para cumplir su función, el tributo tiene que generar una contrafuncionalidad: los dueños de dinero tienen que ser expropiados. ${ }^{8}$ Esta expropiación de dinero es imprescindible para que el sistema económico siga funcionando; pero no por ello deja de generar una resistencia fuerte en los tenedores de dinero a quienes se expropia, ya que todo el entramado social está imbuido de la creencia de que la propiedad privada es esencial (y sin dudas lo es en términos materiales, más allá de las creencias).

La coexistencia en torno al tributo de una contrafuncionalidad y su paralela funcionalidad intrínsecas, explica la constante ambigüedad y conflicto que rodean a la tributación. A la tendencia continua de los actores sociales a quienes se expropia dinero a buscar formas abiertas o solapadas de incumplimiento, se contrapone la constante realización de acciones que refuerzan la expropiación de dinero, como fiscalizaciones, normas que otorgan facultades extraordinarias a la Administración; a la generación de discursos dogmáticos contrarios a la recaudación, se corresponden discursos dogmáticos que apuntan a fortalecer la recaudación, etcétera.

Cabe agregar que, en materia tributaria, como en muchas otras, el conflicto es insoluble: dado que tanto la función recaudatoria como la propiedad privada son irreemplazables para que la estructura económica perviva y se reproduzca, ninguna de las dos puede prevalecer totalmente sobre la otra, por lo que la pugna y el desgaste durarán lo que dure el sistema económico imperante.

\subsection{Las estrategias específicas de configuración y combate del fraude a la ley fiscal}

El tributo como relación social debe recubrirse de la capa del derecho; es decir, como todas las relaciones sociales, debe aparecer mistificado como un conjunto de prohibiciones y permisos bajo formas de textos constitucionales, dogmáticos, legales, reglamentarios, judiciales, etcétera. De manera que el discurso jurídico tributario, en es-

8. En lo que sigue utilizo los términos expropiación, expropiado y otros derivados, como sinónimo de desapoderamiento forzado, no como alusión a la expropiación de bienes a la que se refieren las constituciones, las leyes y la dogmática latinoamericana. 
pecial la ley, acepta e integra las categorías jurídicas a las que me referí antes, así como también debe aceptar el modelo argumentativo exegético (Amatucci, 2001: 597 y ss.; Simón-Acosta, 1985: 143).9 Así, por ejemplo, los impuestos a las rentas normalmente admiten como contribuyentes a las sociedades u otras personas jurídicas. Abstractamente alguien podría pensar que los impuestos podrían ignorar totalmente las personas jurídicas, pero eso hasta ahora nunca ha sucedido, y es porque la categoría persona jurídica es, como indiqué en 2.3.1 una forma mistificada de limitar las pérdidas posibles del capital y evitar la destrucción masiva de éste.

El que la estructura jurídica del tributo se apoye en las grandes categorías jurídicas tradicionales, $\mathrm{o}$-en todo caso- establezca categorías nuevas mediante una selección de propiedades de ciertas relaciones sociales, a la vez que se omiten otras propiedades de la misma relación, fue advertido por Barros Carvalho (1998: 124-127). Sin embargo, lo que Barros Carvalho no indaga es el motivo y la función de escoger algunas propiedades y otras no. Esa forma en que opera el derecho deriva de una función social específica: las propiedades que se seleccionan son las que fortalecen las relaciones sociales económicas imprescindibles para que la estructura económica funcione y se reproduz$\mathrm{ca}$, y se omiten aquellas que pudieran entorpecerla. Volvamos al ejemplo de las sociedades: la propiedad de ser sujeto asegura que los seres humanos que operan con la cara de una sociedad puedan seguir realizando intercambios de mercancías, mientras que la propiedad de ser una limitación de las pérdidas del capital no está dicha expresamente, sino soslayada por expresiones como separación entre los patrimonios social y del socio, limitación de responsabilidad, etcétera.

A propósito, el hecho de que el derecho tributario admita las categorías jurídicas es una invitación a utilizarlas para su función natural de limitar las pérdidas del capital, esta vez defendiéndolo de la expropiación de dinero bajo forma de tributos. Esto se hace a través de la colocación de las personas en las categorías que, según el complejo juego que establecen los textos jurídicos tributarios, se traducen en pagar menos tributos.

Quiere decir que las condiciones para que nazca el fraude a la ley fiscal son creadas por la propia ley fiscal y, es más, son inevitables ya que refieren a condiciones materiales connaturales al sistema económico vigente. Y, por lo demás, las conductas tendientes a parapetarse en formas jurídicas menos costosas son el fruto de modelos de conducta absolutamente centrales para la pervivencia y la reproducción de la estructura social, como lo es la conservación de la propiedad privada y del capital.

La calificación de un conjunto concreto de conductas como un fraude a la ley fiscal es, entonces, una reacción impulsada por el interés recaudatorio contra el interés de preservar la propiedad privada y limitar las pérdidas del capital. Como lo que han hecho las personas que se colocaron en la posición tributaria más ventajosa es seguir puntualmente las categorías jurídicas que la propia ley tributaria recoge, la reacción recaudatoria no puede fundarse en una lectura normal o estándar del texto legal (o cons-

9. La necesidad de apelar a categorías jurídicas tradicionales es un hecho claro también para la dogmática tradicional; para ello, véanse los títulos citados en las referencias bibliográficas. 
titucional o reglamentario). Allí es, entonces, donde se echa mano de fines, principios u otros enunciados: no es que el fraude a la ley sea una violación de fines o una violación de principios, sino que se trata de que el interés recaudatorio debe recubrirse de un fin o un principio para poder operar dentro del derecho.

En ese punto se puede observar, como lo anticipé en 2.3.3, el entronque de los argumentos de defensa del uso estratégico de las formas jurídicas con los programas políticos o ideologías jurídicas. La configuración deliberada de una categoría jurídica fiscalmente más barata se enlaza con el programa liberal-conservador, una de cuyas propuestas centrales es, precisamente, la autonomía de la voluntad, de la que se deriva el enunciado nadie está obligado a adoptar la forma jurídica más costosa (Valdés Costa, 1996: 288; Ferreiro Lapatza, 2003: 507). Del otro lado, el interés recaudatorio puede enlazarse con el programa social intervencionista, dado que éste es proclive a la intervención estatal en las relaciones económicas privadas y el tributo lo es.

El hecho de que una solución definitiva al conflicto sea imposible, por las constantes oscilaciones en el peso relativo de los intereses económicos en juego, llena de dificultades a la dogmática. Ésta debate arduamente qué debe considerarse un ahorro fiscal lícito, un fraude a la ley, una elusión, una evasión o un ahorro fiscal ilícito. Para citar un ejemplo: la figura que en este artículo he descrito y explicado bajo el nombre de fraude a la ley fiscal es igual a la que en algunos manuales se denomina elusión, y en otros evasión, a veces agregándole adjetivos como lícita o ilícita. La dogmática discute si el fraude a la ley es lo mismo que la elusión, si ésta es lícita o ilícita, etcétera. Pero todo este debate no llega a ningún resultado claro ni siquiera en el plano dogmático, como honestamente lo admiten Atienza y Ruiz Manero (2000: 83-84), haciendo suyas expresiones de Rosembuj.

Es que esas oscilaciones en la prevalencia de intereses y funciones opuestas son inherentes al sistema económico, y la dogmática es un discurso que debe ajustarse a las necesidades de ese sistema. Cuando el juez, el dogmático o el abogado emplean una estrategia argumentativa de fraude a la ley, o una estrategia de defensa contra la imputación de un fraude a la ley, están cumpliendo sus respectivos roles sociales a los que están llamados: la función de los juristas profesionales es encauzar, dentro de una práctica social institucionalizada y con argumentos reconocidos dentro de ella, la resolución de conflictos sociales de manera que no hagan estallar el sistema. La falta de consenso es la cara jurídica del juego de funcionalidad y contrafuncionalidad entre tributo y propiedad privada; como ese juego es connatural al sistema, la contraposición de estrategias argumentativas no desparecerá mientras el sistema no lo haga.

En ese juego, a veces cambiar un nombre viste a la estrategia adoptada de una forma más elegante. "Tal conducta no es un fraude a la ley, es una 'economía de opción'», dice alguien que quiere defender la estrategia de pagar menos impuesto aprovechando la formalidad de las categorías jurídicas. «Esa conducta es una evasión ilegítima», dice la Administración fiscal. Pero éstas son siempre operaciones retóricas, lo cual — digámoslo claramente - no les quita su importancia, porque es en esa arena retórica y mistificada del derecho donde se dirime el conflicto social que aparece soslayado. 
A veces, para terminar con las oscilaciones en el predominio de intereses y establecer criterios claros de actuación de los actores sociales, se ensayan otras estrategias más o menos sustraídas a los juegos argumentativos de los juristas. Eso es lo que sucede cuando, aprovechando el prestigio que tiene el discurso del derecho positivo, se dictan leyes que minuciosamente estipulan cuándo y cuánto prevalecen el interés recaudatorio, por un lado, y la propiedad privada del dinero por el otro. Por ejemplo, ésa es la función que tienen las normas sobre precios de transferencia en los impuestos a las rentas empresariales, o las acciones del plan BEPS de la OCDE, ${ }^{10}$ que son soluciones de las legislaciones tributarias nacionales que ese organismo internacional impulsa bajo amenaza de represalias contra los países reluctantes. Lo mismo puede decirse de las reglas sobre precios de transferencia: cuando se realizan operaciones entre partes vinculadas, y para evitar discusiones y litigios por manipulaciones de precios con el fin de disminuir los impuestos totales a pagar, el texto legal fija de antemano definiciones de vinculación y niveles de precios que se tomen, dependiendo de que nos refiramos a uno u otro sujeto, como ingresos o como costos o gastos a efectos de los impuestos a las rentas empresariales.

Vistas en perspectiva teórica, las acciones sugeridas por la OCDE en el plan BEPS, así como las reglas sobre precios de transferencia y otras soluciones semejantes, conforman un tipo de estrategia con el que casi siempre se resuelven las tensiones entre funcionalidades y contrafuncionalidades al seno del capitalismo: las pretensiones contrapuestas son absorbidas mediante un discurso que, aceptado por todos a través de la amenaza de represalias, demarca fronteras que aseguran la recaudación, pero permiten a la vez la movilidad del capital y no eliminan la posibilidad de los propietarios de dinero de limitar sus pérdidas mediante formas jurídicas.

\subsection{El fraude a la ley fiscal y otras estrategias semejantes}

Las similitudes entre el fraude a la ley fiscal y otras figuras dogmáticas semejantes son obvias. En primer lugar, es indudable su proximidad con la recalificación por formas jurídicas inapropiadas, también llamado principio de la realidad, o de sustancia sobre forma, $\mathrm{u}$ otros nombres parecidos. Esta figura no supone propiamente una calificación según la realidad: dada una cierta operación encuadrada voluntariamente por los particulares en una cierta categoría jurídica, un tercero (la Administración o un juez), o inclusive el mismo particular, reubican la operación en otra categoría jurídica. Esta reubicación se realiza a través de la proposición, para cada categoría jurídica, de una serie de propiedades que sólo tienen sentido dentro del discurso jurídico, por lo cual no implica una calificación basada en la realidad, sino un mecanismo que se desarrolla

10. BEPS es la abreviación de la expresión inglesa «base erosion and profits shifting» (erosión de la base y desplazamiento de las utilidades); OCDE es la abreviación de Organización para la Cooperación y el Desarrollo Económicos, organización que agrupa a Estados comprometidos con el modelo económico y político dominante. Los detalles actuales y pasados del plan BEPS pueden consultarse en http://www.oecd. org/tax/beps/. 
internamente en la praxis jurídica, de una categoría jurídica a otra categoría jurídica (Tarsitano, 2008: 854-855). La diferencia entre la recalificación y el fraude a la ley fiscal se produce cuando el jurista no logra encontrar en las categorías mencionadas expresamente por la ley tributaria propiedades que coincidan con aquellas que puedan predicar fácilmente de la operación que analiza. Desde luego que esta limitación se produce simplemente porque ese sujeto que analiza la operación concreta no quiere rebasar la delimitación de una categoría jurídica hecha antes por la dogmática. Si lo deseara podría hacerlo, pero normalmente la praxis jurídica tiende a estabilizarse en los términos fijados por la dogmática, lo cual reduce las posibilidades de éxito de un argumento que no tenga un antecedente dogmático (Alexy, 1989: 255-256). Por tanto, la diferencia entre la recalificación según la realidad y el fraude a la ley fiscal radica en el grado de apego a los argumentos de la dogmática precedente.

También el fraude a la ley fiscal es muy próximo a lo que los juristas llamamos interpretación extensiva de la ley (Guastini, 2014: 170-173). En efecto, en este último caso no se argumenta explícitamente sobre un caso concreto, sino que se aparenta realizar un comentario o exégesis de un término previsto en la ley. Por ejemplo, si un texto legal de un impuesto a la renta menciona como hecho imponible a los intereses, un dogmático, la Administración o un juez podrían extender la aplicación del impuesto a las diferencias entre valor nominal y precio en una cesión de un crédito. La semejanza económica entre las operaciones es notoria: la cesión de un crédito con vencimiento a un plazo, por un precio menor al nominal, es exactamente equivalente a un préstamo a interés garantizado con la cesión del mismo crédito. Dada esa semejanza económica, no debería extrañarnos que la Administración, el juez o un dogmático proclive al interés recaudatorio sostengan que la diferencia entre precio y valor del crédito en la cesión de créditos debe tratarse como un interés en el impuesto a la renta. Argumentativamente, a esa conclusión puede llegar indistintamente: a) sosteniendo que la palabra intereses incluida en el texto de la ley debe entenderse como incluyente también de estas otras diferencias de dinero que económicamente son equivalentes a los intereses; o b) sosteniendo que las partes han realizado un fraude a la ley fiscal, utilizando una forma jurídica cesión de créditos para ubicarse fuera de la letra de la ley, y proceder a aplicar el impuesto según su espíritu.

En la dogmática tradicional se ha advertido que el fraude a la ley fiscal implica algo sustancialmente igual a la interpretación extensiva, como fundamento para restringir la aplicación del fraude al tenor de un «principio de tipicidad» del tributo análogo a la materia penal (Ferreiro Lapatza, 2003: 519-520). En esta tesis se advierte la influencia del programa o ideología liberal-conservadora, que propuse en 2.3.3 tomándolos de Kennedy. En efecto, la idea de una tipicidad del tributo es parte de la concepción general de ese programa de que toda intervención estatal en la economía privada es perniciosa, lo cual es a su vez parte de una visión ideológica (esta vez en sentido marxista) de la sociedad, ya que el tributo mismo no sólo no es pernicioso para el capitalismo, sino imprescindible para su funcionamiento. En todo caso, vemos una vez más la estrategia de apelar a principios para recubrir intereses, en este caso contrarios al fraude a la ley fiscal. 
Finalmente, el fraude a la ley fiscal es muy semejante a la suposición de un vacío y su solución mediante la integración. Kelsen distinguió las llamadas lagunas en sentido estricto, que son las soluciones que el jurista cree subjetivamente buenas, pero que al no estar incluidas en el texto legal se impulsan como aparentes respuestas racionales a un pseudo déficit de regulación; y por otro lado las lagunas técnicas, que son aquellas soluciones imprescindibles para que la ley opere pero que no se han estipulado expresamente (Kelsen, 1997: 254 y ss.). En realidad, todas las lagunas son el fruto de valoraciones políticas del jurista: incluso las lagunas técnicas parten del supuesto de que lo no regulado debe tener una solución unívoca, lo cual es una de las tesis ideológicas del positivismo, ya que lo no regulado por el derecho no tiene por qué estarlo en ningún sentido. Pero más allá de eso, la suposición de vacíos siempre significa que un juez, o un dogmático, o la Administración, desean una decisión en un cierto sentido y no pueden justificarla a partir de lecturas más o menos convencionales de un texto de derecho positivo. Por lo tanto, se introduce la solución nueva buscando analogías, esto es, parecidos, con los casos y soluciones que se pueden derivar de una lectura corriente de otros textos. El proceso argumentativo es similar al del fraude a la ley, la recalificación y la interpretación extensiva; pero sobre todas las cosas, todos pueden desembocar en el mismo resultado.

Por lo tanto, estamos simplemente frente a diferentes estrategias de argumentación para abordar problemas iguales, y llegar a soluciones iguales. La muestra de que en sustancia siempre estamos en el mismo proceso es la imposibilidad de la dogmática tradicional de construir definiciones convincentemente distintas de una y otra figura (González, 1997: 48-49).

¿Cuál de estas modalidades predomina en cada caso? A priori no es posible decirlo, ya que todas cumplen funciones similares; lo que se puede comprobar es la existencia de tradiciones en la práctica jurídica que, para grupos de casos típicos, se inclinan por algunas modalidades antes que otras. Vuelvo al ejemplo imaginario del préstamo a interés y la cesión de créditos por un precio inferior al valor nominal: aunque con distintas estrategias se llegue a un mismo resultado, parece más probable que el interés recaudatorio tendiente a gravar esa renta se incline por la interpretación extensiva, ya que se mantiene la apariencia de que la solución no se desapega de la regla de respetar la ley. Pero como las diferencias son simplemente retóricas, no puede descartarse en absoluto que ese interés apunte a sostener - por ejemplo- que en sustancia la diferencia entre precio y valor nominal del crédito es un interés (aplicación del principio de la realidad), o que se eligió una modalidad de negocio que se coloca deliberada y artificialmente fuera del hecho imponible (fraude a la ley fiscal).

La semejanza y confusión entre estas figuras no es, por lo tanto, una deficiencia de la jurisprudencia, como se ha sostenido por algún sector dogmático (Carrasco Perera, 2016: 300 y ss.). En efecto, las fronteras entre la integración, el fraude, la interpretación, etcétera, son borrosas, porque no se trata sino de herramientas discursivas puestas al servicio de los intereses en juego. La movilidad de los intereses desemboca, según la ocasión, en una u otra estrategia, y esa es la única explicación de que dichas figuras 
tengan un uso errático. Todo debate dogmático acerca de cuándo corresponde - por ejemplo- hablar de un fraude a la ley fiscal en vez de cualquier otra figura, es totalmente estéril en el plano teórico. Sí tiene sentido como una pieza más en el juego estratégico que pretende comentar, pero en el que en realidad está inmerso: las disquisiciones acerca de cuándo hay o no fraude, inadecuación de formas, etcétera, son sólo argumentos que se lanzan al conocimiento público para que los juristas profesionales los usen como refuerzo de la estrategia que elijan.

Tampoco tiene sentido, en el plano teórico, proponer que en materia tributaria los juristas tienen restricciones específicas como la reserva de ley absoluta o la prohibición de la analogía (Carrasco Perera, 2016: 303-305). Aun cuando los textos positivos de un país, por ejemplo, prohíban la analogía, eso supone una restricción estrictamente argumentativa en el plano dogmático, en la medida en que se esté dispuesto a aceptar sin discusión proclamas legislativas de esa índole. Si el fraude a la ley se concibe como un choque de estrategias para viabilizar pretensiones contrapuestas que desbordan el tipo de argumentación estándar, el mismo se producirá exista o no un texto que prohíba algo semejante a él: si no puede hallarse una respuesta al problema con los cánones discursivos normales (esto es, manejando el texto legal con lecturas normales), los intereses involucrados buscarán y hallarán otros caminos semejantes, cambiando — si se quiere- la denominación jurídica de su estrategia.

\subsection{Fraude a la ley fiscal y otros nombres similares (elusión, evasión, economía de opción, etcétera)}

En otro orden de cosas, la noción de ilícita tomada de Kelsen que adopté en el apartado 2.2 disuelve todas las discusiones de la dogmática y la jurisprudencia tributarias acerca de la evasión ilícita o ilegítima, la elusión lícita, la economía de opción, etcétera.

Primero, no hay actos lícitos ni ilícitos en sí, o de antemano: la única frontera entre la licitud y la ilicitud está dada por la aplicación de una sanción por la autoridad, y no existe antes de que esa sanción se produce. Por lo tanto, ninguna conducta de los sujetos pasivos es lícita ni ilícita en sí. A lo sumo, las cosas que de antemano pueden, de algún modo, hacer vislumbrar una sanción son:

- Una conducta reiterada de los tribunales o la Administración de sancionar ciertas conductas tributarias de los particulares.

- La existencia de textos positivos o dogmáticos que induzcan a establecer sanciones (es decir, a conformar como prohibidas) algunas conductas de los particulares que desemboquen en menores pagos de tributos.

Pero, como en todos los campos, estas previsiones son simplemente estadísticas o probabilísticas. Desde luego que valorar las recomendaciones legislativas o dogmáticas simplemente en función de mediciones probabilísticas tiene una considerable importancia para la práctica profesional de los juristas, aun cuando la valoración de los argumentos o soluciones como tales sea imposible y/o irrelevante. 


\subsection{El fraude de contenido fiscal realizado por las autoridades}

El hecho de que la mayoría de las veces sean los particulares los que inician la apuesta estratégica al carácter formal del derecho, no impide que muchas veces el Parlamento o la Administración hagan una apuesta análoga.

Más arriba mencioné un ejemplo: el del hipotético Parlamento que elude la prohibición constitucional de un impuesto a las utilidades no distribuidas, creando un impuesto económicamente idéntico, pero formalmente estructurado como impuesto a los resultados acumulados entendidos como activos de la sociedad. Otro ejemplo podría ser el de la Administración tributaria que mantiene una postura rechazada sistemáticamente por los tribunales con competencia para dejar sin efecto sus resoluciones, en un país en el que una sentencia tiene efecto exclusivamente para el caso concreto. El interés recaudatorio puede anclarse estratégicamente en el texto constitucional o legal que limita el alcance de la sentencia, y decidir una y otra vez en el sentido rechazado por los tribunales apostando a que sólo una minoría de los contribuyentes estará dispuesto a llevar el caso ante un tribunal. Quizás los oponentes al interés recaudatorio podrían utilizar - o crear, si nadie lo hizo hasta ese momento- un principio como la Administración debe actuar conforme a las sentencias, más allá del caso concreto, para justificar un fraude a la ley o la Constitución por parte de esa Administración.

\section{Conclusiones}

La conclusión específica ya fue expuesta varias veces en el trabajo: desde el punto de vista de una teoría del derecho, el fraude a la ley, así como otras figuras próximas, son confrontaciones de estrategias argumentativas para eludir y contrarrestar la elusión de ciertas prohibiciones. En materia tributaria, se trata de choques de estrategias para, por un lado, defender la propiedad privada del dinero y la conservación del capital, y por otro lado de recaudar para mantener estable el sistema de precios monetarios. $\mathrm{Su}$ interés, como toda tesis teórica, radica en una contribución a la comprensión de un fenómeno, en este caso social.

Los discursos profesionales como la dogmática o la jurisprudencia probablemente no necesiten llegar a ese grado de análisis para lidiar con el fraude a la ley, ya que seguramente estén más interesadas en generar guías de uso de dichas estrategias. Empero, los desarrollos de este trabajo pueden no carecer de interés para quien se desenvuelva en la práctica interna del derecho; por ejemplo, podría encontrarse alguna utilidad interna al pronóstico de que estas estrategias entran en escena cuando es insuficiente el juego argumentativo exegético y las categorías jurídicas estándar.

Por otro lado, desde el punto de vista teórico, el desarrollo del fraude a la ley refuerza la concepción del derecho como un campo en el que confrontan permanentemente estrategias que defienden intereses contrapuestos. Es más: se puede extrapolar, generalizándola, la tesis que he desarrollado, y afirmar que la práctica del derecho es invariablemente estratégica. Si ello es correcto, en esta práctica no se trata de hallar soluciones 
objetivamente sostenibles, sino soluciones aptas para proteger grupos de intereses, de las que luego se buscan justificaciones sostenibles. Y eso no sólo descarta la posibilidad de soluciones normativamente correctas por la forma en que se determina su contenido, al estilo de Dworkin (2005: 273 y ss.), sino que también requiere dejar de lado la corrección procedimental de una solución como consecuencia de una secuencia de actos en el que los argumentos contrapuestos se consideran cooperativamente, como lo sostiene Habermas (1998: 293 y ss.).

En efecto, una solución jurídica deriva de la prevalencia de un grupo de intereses en función del peso social relativo que logren. Los argumentos para justificar la solución vienen detrás, como vestiduras racionales; pueden tener la nota de universalidad que la teoría del discurso propone como medida de racionalidad normativa, pero ello no es decisivo para su aceptación. Cierto que los argumentos admisibles son, como dice Habermas, el fruto de una práctica profesional duradera y consolidada, en la que el aprendizaje universitario del derecho cumple un rol fundamental. Pero el elenco de conflictos, las soluciones posibles, y las finalmente adoptadas, no son la consecuencia de la práctica argumentativa de los juristas, sino de las confrontaciones sociales en sí, que sólo son mediadas simbólicamente por el derecho. No hay, por ende, un esfuerzo argumentativo cooperativo, sino una aceptación del escenario donde se desarrollará la puja (los procedimientos establecidos de tipo judicial, parlamentario, administrativo, etcétera), y sobre todo el acatamiento a la autoridad que decide el conflicto.

\section{Referencias}

Alchourrón, Carlos y Eugenio Bulygin (1998). Introducción a la metodología de las ciencias jurídicas y sociales. Buenos Aires: Astrea.

Alexy, Robert (1989). Teoría de la argumentación jurídica. Madrid: Centro de Estudios Constitucionales.

Alfonsín, Quintín (1953). Teoría del derecho internacional privado. Montevideo: Facultad de Derecho y Ciencias Sociales.

Amatucci, Andrea (2001). "La interpretación de la ley tributaria». En Andrea Amatuccci (dir.), Tratado de Derecho Tributario. Tomo 1. Bogotá: Temis.

Atienza, Manuel y Juan Ruiz Manero (1996). Las piezas del derecho. Barcelona: Ariel.

-. (2000). Ilícitos atípicos. Madrid: Trotta.

Barros Carvalho, Paulo de (1998). Derecho Tributario. Fundamentos jurídicos de la incidencia. Buenos Aires: Ábaco.

BLANCO, Andrés (2015). «Función del derecho, principios y derechos subjetivos». Ruptura. Revista Interdisciplinaria de Análisis Jurídico, 6: 49-8o.

Bougrine, Hassan y Mario Seccareccia (2006). «El papel de los impuestos en la economía nacional». En Pierre Péguy y Louis-Pilippe Rochon (coordinadores), Teorías económicas poskeynesianas. Madrid: Akal.

Brooks, Neil (1997). «The responsbility of judges in interpreting tax legislation». En Grame Cooper (editor), Tax avoidance and the Rule of Law. Melbourne: IBFD. 
CARnap, Rudolf (1993). «La superación de la metafísica mediante el análisis lógico del lenguaje». En A. J. Ayer y otros, El positivismo lógico. Madrid: Tecnos.

Carrasco Perera, Ángel (2016). Tratado del abuso de derecho y el fraude de ley. Pamplona: Civitas Thomson-Reuters.

Correas, Oscar (2003). Crítica de la ideología jurídica. México: Coyoacán.

Courtis, Christian (2006). «Detrás de la ley. Lineamientos para el análisis ideológico del derecho». En Christian Courtis (editor), Observar la ley. Ensayos sobre metodología de la investigación jurídica. Madrid: Trotta.

Dworkin, Ronald (1993). Los derechos en serio. Barcelona: Planeta-Agostini.

-. (2005). El imperio de la justicia. Barcelona: Gedisa.

FAGET, Alberto (1981). «La forma jurídica inadecuada y el fraude a la ley fiscal». Revista Tributaria (Montevideo), 42.

Ferreiro Lapatza, José Juan (2003). «Economía de opción, fraude de ley, sanciones y delito fiscal». En Paulo Barros Carvalho (editor), Tratado de Derecho Tributario. Lima: Palestra.

Frege, Gottlob (1998). Ensayos de semántica y filosofía de la lógica. Madrid: Tecnos.

GonzÁlez, Eusebio (1997). La interpretación de las normas tributarias. Pamplona: Aranzadi.

GuAstini, Riccardo (2014). Interpretar y argumentar. Madrid: Centro de Estudios Políticos y Constitucionales.

Habermas, Jürgen (1998). Facticidad y validez. Sobre el derecho y el estado democrático de derecho en términos de teoría del discurso. Madrid: Trotta.

Kennedy, Duncan (1997). A critique of adjudication. Cambridge, Massachusetts: Harvard University Press.

Kruse, Heinrich Wilhelm (2002). «El ahorro de impuesto. La elusión fiscal y la evasión». En Andrea Amatucci (editora), Tratado de Derecho Tributario. Tomo 2. Bogotá: Temis.

Luhmann, Niklas (1983). Sistema jurídico y dogmática jurídica. Madrid: Centro de Estudios Constitucionales.

Kelsen, Hans (1997). Teoría pura del derecho. México: Porrúa.

Marx, Karl (2000). El capital. Tomo 3. México: Fondo de Cultura Económica.

Messineo, Francesco (1979). Manual de derecho civil y comercial. Tomo 2. Buenos Aires: Ediciones Jurídicas Europa-América.

PAšukanis, Evgeni (1976). Teoría general del derecho y marxismo. Barcelona: Labor.

Quine, Willard V. (2002). La relatividad ontológica y otros ensayos. Madrid: Tecnos.

Rosembuj, Tulio (1994). El fraude de ley y el abuso de las formas en el derecho tributario. Madrid: Marcial Pons.

Simón Acosta, Eugenio (1985). El derecho financiero y la ciencia jurídica. Bolonia: Real Colegio de España.

TARsitano, Alberto (2001). «Presupuestos, límites y consecuencias de la recaracterización tributaria de los actos jurídicos. La experiencia argentina». En Osvaldo Casás 
(coordinador), Interpretación económica de las normas tributarias. Buenos Aires: Universidad Austral, Ábaco.

Tarsitano, Alberto (2008). «Teoría de la interpretación tributaria». En César García

Novoa y Catalina Hoyos Jiménez (coordinadores), El tributo y su aplicación: Perspectivas para el siglo XXI. Tomo I. Buenos Aires: Marcial Pons.

VAldés Costa, Ramón (1996). Curso de derecho tributario. Bogotá: Depalma, Temis, Marcial Pons.

Weber, Max (1998). Economía y sociedad. México: Fondo de Cultura Económica.

\section{Sobre el autor}

Andrés Blanco es doctor en Derecho y Ciencias Sociales por la Universidad de la República Oriental del Uruguay. Es profesor adscripto de Derecho Financiero de la Facultad de Derecho de la Universidad de la República Oriental del Uruguay. El presente artículo se realizó en el marco del régimen de extensión horaria de docentes de dicha universidad.Su correo electrónico es andresblanco@vera.com.uy. 